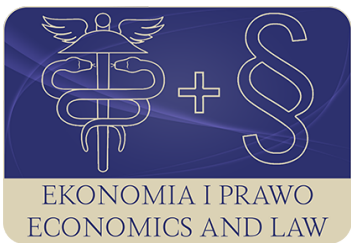

EKONOMIA I PRAWO. ECONOMICS AND LAW

Volume 19, Issue 2, June 2020

p-ISSN 1898-2255, e-ISSN 2392-1625

www.economicsandlaw.pl

ORIGINAL ARTICLE

received 15.03.2020; revised 11.05.2020; accepted 30.06.2020

Citation: Szulc, E. (2020). Spatio-temporal modelling of economic phenomena in the context of reducing the dimensions of the random field. Ekonomia i Prawo. Economics and Law, 19(2):

333-354. doi:10.12775/EiP.2020.023.

\title{
Spatio-temporal modelling of economic phenomena in the context of reducing the dimensions of the random field
}

\author{
ELŻBIETA SZULC \\ Nicolaus Copernicus University in Toruń, Faculty of Economic Sciences and Management, \\ Department of Econometrics and Statistics, ul. Gagarina 13A, 87-100 Toruń, Poland \\ ๑eszulc@umk.pl \\ orcid.org/0000-0001-5636-0724
}

\begin{abstract}
Motivation: Clear spatial diversity and high variability in time of economic phenomena and the fact that they show dependencies in space and time dimensions, as well as the spatio-temporal dependencies, lead to the consideration of the phenomena in terms of random fields. On the other hand, applying methods and tools from the field of multidimensional stochastic processes called random fields is difficult due to the specificity of the economic data, in particular to a low number of the observations in space. Hence, there arises the problem of the reduction of the dimensions (especially the space dimension) of the random fields which define economic phenomena.

Aim: The aim of the paper is to discuss a model that will reflect the structure of spatial connections and dependence in the spatio-temporal process, while reducing the dimension of space as a non-random argument of the random field. As a result, the set of $\mathrm{N}$ time series will be analysed. Therefore, we build a multiple-equation model of autoregressive character with a spatial structure of dependence. In the paper we discuss the advantages and cognitive values of such an approach to the study of economic phenomena in spa-

tio-temporal terms.

Results: The empirical example concerns the unemployment rate in Poland across provinces (NUTS2) in the period from January 2011 to April 2019. The data create spatio-temporal series which is the realisation of the two-dimensional random field. The model building strategy is based on a vector autoregressive (VAR) specification, where there are as many time series as the provinces. The study shows that the use of the concept of the conditional, with regard to space dimension, random field simplifies the economet-
\end{abstract}


ric analysis of the spatio-temporal process under consideration without losing the accuracy of the description of his basic properties.

Keywords: spatio-temporal process; random field; model with spatial structure of dependence JEL: C10; C31; C33

\section{Introduction}

In the investigation of the spatio-temporal phenomena it is important to simultaneously refer to their locations in space and time. In the case of economic phenomena, it concerns e.g. unemployment rate, salaries, investments, GDP per capita, and the like. Therefore two-dimensional variables related with the spatial locations $\mathbf{s}=\left(\mathrm{s}_{1}, \mathrm{~s}_{2}\right) \in \mathbf{S} \subset \mathbf{D}$ and time $t \in \mathrm{T}$ are being analysed. Collections of the double indexed variables create two-dimensional random fields, which provide natural foundation for description of the phenomenon variability in space $\mathbf{S} \times \mathrm{T}$.

The aim of the paper is to recommend a model that will reflect the structure of spatial connections and dependence in the spatio-temporal process, while reducing the dimension of space as a non-random argument of the random field. In this approach the important fact is that it does not require spatial stationarity (homogeneity), it puts off the dimensionality problem and uses availability of a large number of data in time but a small number of observations in space.

The empirical example concerns the unemployment rate in Poland across provinces (NUTS2) in the period from January 2011 to April 2019. From the methodological point of view, the unemployment phenomenon can be considered as an $r$-dimensional random field, in particular $r=1,2,3$. When $r=1$, a time series of unemployment rates is obtained $\{\mathrm{y}(t), t=1,2, \ldots, \mathrm{T}\}$, which is the individual realisation of the stochastic process $Y(t), t \in T \subset R$, or the spatial series $\left\{\mathrm{y}\left(\mathbf{s}_{i}\right), \mathbf{s}_{i}=\left[\mathrm{s}_{1 i}, \mathrm{~s}_{2 i}\right], i=1,2, \ldots, \mathrm{N}\right\}$, being the realisation of the spatial process $\mathrm{Y}(\mathbf{s}), \mathbf{s} \in \mathrm{D} \subset \mathrm{R}^{2}$. In turn, when $r=2$, spatio-temporal series $\left\{\mathrm{y}\left(\mathbf{s}_{i}, t\right), \mathbf{s}_{i}=\left[\mathrm{s}_{1 i}, \mathrm{~s}_{2 i}\right]\right.$, $i=1,2, \ldots, \mathrm{N}, t=1,2, \ldots, \mathrm{T}\}$ as realisations of the two-dimensional random field $Y(s, t), s \in D \subset R^{2}, t \in T \subset R$ are obtained. Adding another argument, such as for instance age group, increases the dimension of the unemployment field to $\mathrm{r}=3$. It is also possible to take into account other non-random arguments of the unemployment random field. The starting point of the presented analysis is to treat the unemployment as the spatio-temporal random field. Next, the argument of space referring to the concept of conditional random field is reduced, and under a vector autoregressive (VAR) specification a dynamic model with spatial structure of dependence is obtained. In the general VAR model a spacetime hierarchy which is almost as natural as the purely temporal hierarchy is considered. 


\section{Literature review}

The using of the random field theory for economic research is an approach known in literature, e.g.: Arbia (1989; 2006), Arbia \& Prucha (2013), Arbia et al. (2008; 2010; 2013), Bronars \& Jansen (1987), Case (1991), Case et al. (1993), Christakos (2017), Conley (1999), Conley \& Ligon (2002), Conley \& Topa (2002), Dahl \& Gonzalez-Rivera (2003a; 2003b), de Luna \& Genton (2004), Elhorst (2010; 2012; 2014), Guyon (1995), Ippoliti et al. (2013), Jenish \& Prucha (2009), Knopov (1999), Nummelin (2000), Quah (1993), Topa (2001), Vega \& Elhorst (2014). Among Polish authors, for example, Przybycin (1992) and Zieliński (2002) should be mentioned, and the works by the author of the paper. However, such an approach is still uncommon.

The modelling of economic phenomena as the spatial or spatio-temporal random fields needs many problems to be solved. There are conditions practically difficult to be satisfied, e.g. the conditions of stationarity, homogeneity, isotropy ${ }^{1}$. Such assumptions have usually been made in the spatial and spatio-temporal literature (for instance SAR models, or STAR models as well as their generalizations in the form SARMA or STARMA, the basis for which was founded at the turn of the eighties and nineties of $20^{\text {th }}$ century by Anselin (1988), Bennett (1979), Pfeifer \& Deutsch (1980)). Moreover, the number of the spatial units, for which the statistical data is available, is usually small ${ }^{2}$.

The observations referring to the spatial units create the spatial distributions of data, in which spatial patterns of dependence are exposed. Therefore, the idea of the spatial autocorrelation came into existence (see e.g. Cliff \& Ord, 1973). A special character of the autocorrelation in space is underlined, pointing to an important characteristic feature. It is about the lack of natural ordering on the line: past - present - future. Thus, multi-directionality of the connections and dependence is pointed out. From that there come some difficulties in the matter of the spatial autocorrelation measurement and testing. Another important concept is the space-time autocorrelation which is even more natural than the purely spatial autocorrelation. It is logically justified and supported by the empirical observations that the phenomena in the near locations interact over time, and not 'instantaneously', because the realisation of the dependence

${ }^{1}$ A random field $\{\mathrm{X}(\mathbf{s}), \mathbf{s} \in \mathbf{S}\}$ is said to be stationary/homogeneous/isotropic of order 2 (in a weak sense) if, for each subset $\left(\mathbf{s}_{1}, \mathbf{s}_{2}, \ldots, \mathbf{s}_{\mathrm{N}}\right)$, its moments up to order 2 do not change when the subset is subject to translations or rotations. Stationarity (homogeneity) of order 2 , therefore, implies that the mean and the variance of a random field do not depend on $\mathbf{s}$ and that the spatial covariances of the random field $\gamma\left(\mathbf{s}_{i}, \mathbf{s}_{i}\right)$ depend only on the distance between $\mathbf{s}_{i}$ and $\mathbf{s}_{j}$ and not on their absolute position (location) in the plane (Arbia, 2006, pp. 45-46).

2 The data refer to the spatial units delimited by the administrative division, i.e. to provinces, counties or districts. Limited number of the units and their different sizes and shapes cause that econometric analyses of such data become difficult. 
in space needs a time lapse ${ }^{3}$ (see e.g. Epperson, 2000; Giacomini \& Granger, 2004; Haggett et al., 1977).

An interesting approach to modelling of the spatio-temporal phenomena is the vector autoregressive model with spatial structure proposed by de Luna \& Genton $(2004 ; 2005)$. The model idea comes from the vector autoregressive (VAR) model commonly used in multivariate time series analysis. The difference is that a single variable observed at several spatial regions of a lattice at the same time is modelled, not several variables observed at the same time. The model is recommended when the available spatio-temporal data is rich in the time dimension but sparse in the spatial dimension. De Luna \& Genton (2004; 2005) used this concept for analysis of spatio-temporal data on U.S. unemployment rates and in environmental studies analysing wind speed data and carbon monoxide atmospheric concentrations. Also the author of the paper has already made the first attempts to use of this concept for analysis of unemployment rate in Poland (Szulc, 2006; 2008). In turn, André et al. (2016) applied the VAR model to analysis of global solar radiation.

\section{Methods}

The methodology used in the study includes two closely related concepts, the socalled conditional random fields ${ }^{4}$ and the vector autoregressive models with spatial structure of connections.

\subsection{Conditional random fields in the analysis of the structure of spatio-temporal processes: some remarks}

It is established, that the spatial unit $i$ is located at the point $\mathbf{s}_{i}$ in the Euclidian space $\mathrm{R}^{2}$. The locations of the $i$-th unit at the time $t$ are denoted as $\left(\mathbf{s}_{i}, t\right)$. The values of the random variable $\mathrm{Y}_{\mathbf{s}_{i, t}}$ at the collection of locations $\left\{\mathbf{s}_{i}, t\right\}_{i=1}^{\mathrm{N}}$ for $t=1$, $2, \ldots, \mathrm{T}$ are observed. The observations are designated by $y_{s_{i}, t}$. The random variable $\mathrm{Y}_{\mathbf{s}_{i}, t}$ associated with the spatial position $\mathbf{s}_{i}$ and with the time point $t$ is called the spatio-temporal random field.

For each established location $s_{i}$ the random variable $Y_{\text {t }}$, i.e. the stochastic process, is obtained. Thus $\mathrm{Y}_{s_{i}, t}$ may be seen as the vector $\mathrm{Y}_{t}=\left[\mathrm{Y}_{s_{1}, t}, \mathrm{Y}_{s_{2}, t}, \ldots, \mathrm{Y}_{s_{\mathrm{N}}, t}\right]$. Likewise, the random variable $\mathrm{Y}_{s_{i,},}$, i.e. the spatial stochastic process, for successive $t$, may be considered, and then $\mathrm{Y}_{s_{i}}=\left[\mathrm{Y}_{s_{i},}, \mathrm{Y}_{s_{i}, 2}, \ldots, \mathrm{Y}_{s_{i}, \mathrm{~T}}\right]$ is obtained.

3 This is a common assumption accompanying the STAR or STARMA models mentioned above.

4 The conditional random field is understood as a random field obtained as a result of establishing any non-random argument or several non-random arguments simultaneously. Considering conditional random fields in this sense is the most common manifestation of the reduction of dimensions of random fields, observed in practice, when the economic phenomena are analysed. 
$\mathrm{Y}_{., t}$ may be named the conditional random field with regard to space. Respectively, $\mathrm{Y}_{\mathrm{s}_{i},}$, may be treated as the conditional random field with regard to time.

In the situation, when there is the data collected at few spatial regions but many in time, the time series may be investigated for each spatial unit separately, i.e. with the use of the concept of conditional, with regard to space, random field, mentioned above. It should be emphasised that the modelling of the time series for each spatial unit separately is reasonable only in the case of the independent conditional random fields. It is difficult to achieve in the analyses of the economic phenomena. In such approach, in the appropriate models the time dependence is taken into account, but the spatial dependence is not considered. Similarly, the time trends may be investigated for the individual time series, and by comparing the results obtained, conclusions about the spatio-temporal trends can be drawn. Fitting the appropriate trend function for each time series, e.g. the polynomial function, leads to elimination of the time trends from the data, but does not guarantee the spatial stationarity (homogeneity) in terms of the mean of the process analysed. Only if the same function described the changes in the mean values, simultaneous elimination of the spatio-temporal trend would be possible.

\subsection{Vector autoregressive models with spatial structure: theoretical background}

The autoregressive (AR) models in the time dimension are constructed assuming that the dependence decreases along with the growth of the distance between the observations of the process considered (the values of the time series). Likewise, in the models of (auto)dependence for the spatial processes (spatial autoregressive, SAR), there is the principle that the dependence is characterised by the distance between the spatial locations of the observations ${ }^{5}$. If the locations $\mathbf{s}_{i}$ and $s_{j}$ are 'close', then the random variables $\mathrm{Y}_{s_{i}}$ and $\mathrm{Y}_{\mathbf{s}_{j}}$ may be strongly correlated. On the contrary, as the distance between $\mathbf{s}_{i}$ and $\mathbf{s}_{j}$ increases, the random variables $\mathrm{Y}_{s_{i}}$ and $\mathrm{Y}_{s_{j}}$ become closer to being independent. Since it is not quite clear how to measure the space-time distance ${ }^{6}$, the modelling of the spatio-temporal processes is difficult ${ }^{7}$. Moreover, the space-time data usually re-

${ }^{5}$ In their search of the appropriate ways of identification and modelling of the spatial (auto)dependence, researchers try to structure the spatial data in a similar way to the time series. The basis of the investigation of the spatial autocorrelation, as much as of the time autocorrelation, is the assumption, that the (auto)dependence decreases with the distance growth.

6 The two-dimensional geographical space is multilateral in nature. Time is unidirectional, and in the space - time system time is not simply the additional dimension.

7 The important assumption, mentioned in Section 2, is that the phenomena in the near locations interact over time, and not 'instantaneously'. In other words, the realisation of the dependence in space needs a lapse of time. In this context, the notion of the space- 
fer to a large number of the observations 'over time' and to a small number of the spatial units.

An alternative for the total spatio-temporal autoregressive model is the vector autoregressive model with spatial structure proposed by de Luna \& Genton (2004; 2005).

It is assumed that observations $y_{s_{i}, t}$ are made at locations $\mathbf{s}_{i}, i=1, \ldots, \mathrm{N}$, and times $t=1, \ldots, \mathrm{T}$. The vector autoregressive model $\operatorname{VAR}(\mathrm{p})$ takes the form (de Luna \& Genton, 2004, p. 282; 2005, p. 549):

$$
\mathbf{y}_{t}-\boldsymbol{\beta}=\sum_{i=l}^{p} \mathbf{R}_{i}\left(\mathbf{y}_{t-i}-\boldsymbol{\beta}\right)+\varepsilon_{t},
$$

where:

$\mathbf{y}_{t}=\left[y_{s_{1}, t}, y_{s_{2}, t}, \ldots, y_{s_{\mathrm{N}}, t}\right]^{\prime}-$ the vector of the observations $y_{s_{i}, t}$;

$\boldsymbol{\beta}=\left[\beta\left(\mathbf{s}_{1}\right), \beta\left(\mathbf{s}_{2}\right), \ldots, \beta\left(\mathbf{s}_{\mathrm{N}}\right)\right]^{\prime}-$ the vector of spatial effects, representing a spatial trend;

$\boldsymbol{\varepsilon}_{t}$ - the N-dimensional white noise, for which $\mathrm{E}\left(\boldsymbol{\varepsilon}_{t}\right)=0 ; \mathrm{E}\left(\boldsymbol{\varepsilon}_{t} \boldsymbol{\varepsilon}_{t}^{\prime}\right)=\boldsymbol{\Sigma}_{\varepsilon}$, and $\mathrm{E}\left(\boldsymbol{\varepsilon}_{t} \boldsymbol{\varepsilon}_{u}^{\prime}\right)=0$ for $t \neq u, \boldsymbol{\Sigma}_{\varepsilon}-$ the $\mathrm{N} \times \mathrm{N}$ matrix of spatial covariances;

$\mathrm{R}_{i}, i=1, \ldots, \mathrm{p}-$ the $\mathrm{N} \times \mathrm{N}$ parameter matrices;

$\mathrm{p}$ - the order of the autoregression in time.

The model (1) is assumed to be stationary in time but it does not assume any spatial stationarity or isotropy (the matrix $\boldsymbol{\Sigma}_{\varepsilon}$ can represent nonstationary spatial covariances). It is important because the time nonstationarity can be easily removed e.g. by the use of a polynomial function in time (and eventually by inclusion of the seasonal component $)^{8}$. The removal of spatial nonstationarity would be much more difficult to do. In the model construction the key issue is

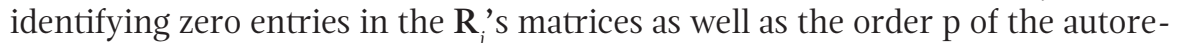
gression. Including in the each equation the explanatory variables, the information about an ordering of the neighbours of each considered location in the space is used.

Model building strategy is as follows. The vector $\mathrm{Y}_{t}=\left[\mathrm{Y}_{\mathrm{s}_{1}, t}, \mathrm{Y}_{\mathrm{s}_{2}, t}, \ldots, \mathrm{Y}_{\mathrm{s}_{\mathrm{N}}, t}\right]$ defined as above is considered. The equations of the model are constructed independently for each separated spatial unit according to a spatio-temporal ordering of the units to determine a hierarchy in which the components of the vector $Y_{t}$ are introduced into the model ${ }^{9}$. The basic of the spatial ordering is the distance between the units, e.g. the geographical distance ${ }^{10}$. The natural

time autocorrelation becomes a more natural concept than the so-called purely spatial autocorrelation.

8 The deterministic trends can be removed also by differencing with $\nabla^{\text {d }}$, i.e. the classical time series difference operator of order d. Periodic time trends or cycles may be tackled by taking differences as well (de Luna \& Genton, 2005, p. 551).

9 In the general vector autoregressive model, a space-time hierarchy which is almost as natural as the purely temporal hierarchy is considered (de Luna \& Genton, 2005, p. 549).

10 Other orderings can be considered as well. De Luna \& Genton (2004, p. 283) indicate orderings based on the length of common border between two spatial regions (see also 
order of 'neighbourhood' of the spatial units is established for the given unit. Finally, the $\mathrm{N} \times \mathrm{N}$ matrix ordering all the spatial units with respect to the given unit is obtained. Table 3 presents the matrix of 'distance' used in establish further the spatio-temporal ordering for provinces considered. For instance, the first row of the matrix presents the neighbourhood order for Dolnośląskie (Lower Silesia) province.

The variables $\mathrm{Y}_{\mathbf{s}_{i}, t}$ are introduced into the model sequentially, according to the natural spatio-temporal order, i.e. firstly $\mathrm{Y}_{\mathrm{s}_{i}, t-1}$, in the spatially defined order for $l=1$, secondly, in the spatially defined order again, for $l=2$, etc. The 'neighbours' of the given unit connected in space and time are established on the basis of the partial correlations. It means that the new variables are introduced into the model so long as the correlations are significantly different from zero ${ }^{11}$. The spatio-temporal partial correlation denotes here the correlation between the established element of the vector $Y_{t}$ and it's another element in the time lag $l$, excluding the impacts of the variables introduced before.

\section{Results of the spatio-temporal analysis of unemployment}

The empirical analysis concerns the unemployment rate in Poland across provinces (NUTS2) in the period from January 2011 to April 2019. The data was downloaded from the database of the Statistics Poland (2019). The statistical sample consists of 100 time observations for each from 16 spatial units, i.e. of 1600 observations together. The 16 time series considered create the realisations of the processes which enter into the vector defining the spatio-temporal process (two-dimensional random field).

First the trend-seasonal and autoregressive structure was investigated, separately for each time series ${ }^{12}$. Table 1 presents the results obtained. From them we can see that the time series of unemployment rates show the deterministic trend and monthly seasonality. After removing these components, the residuals showed autocorrelation and the univariate autoregressive model for each province has been fitted. Then the residuals received from the fitted models were examined. The question was whether they created the space-time white noise.

Haining, 1990) or orders motivated by dynamical/physical knowledge about the underlying process. In the context of unemployment analysis, the basis of an ordering regions can be e.g. socio-economic distance by Conley \& Topa (2002).

11 An approximate test for $\rho_{s}(h)=0$, where $h$ denotes distance in the space-time order, is obtained by noting that, under joint normality of the variables, $\hat{\rho}_{s}(h) \sqrt{(n-h) /\left(1-\hat{\rho}_{s}(h)\right)^{2}}$ is $t$-distributed with $n-h$ degrees of freedom, where $n$ denotes the sample utilized (de Luna \& Genton, 2005, p. 553).

12 For this purpose, the standard statistical techniques, such as: t-statistics, F-test, autocorrelation and partial autocorrelation functions were used. The parameters of the relevant models were estimated with least squares. 
The simultaneous correlations (cross-correlation) of the residuals appeared statistically significant. Most of the residual correlations at time lag 1 were significantly different from zero as well (see table 2). The correlations at time lags larger than 1 were low and mostly insignificant. This means that the time series data analysis for each province separately is not sufficient for discovering the full (auto)dependence structure of the unemployment rates. There is the spatio-temporal dependence which should be taken into consideration in an appropriate model of the process.

In this investigation the spatio-temporal dependence has been established with the use of the VAR model with spatial structure as was described in Section 3. The starting point of the analysis was establishing the spatial structure of the connections between the provinces. The structure is given in table 3. Each row of the table 3 presents the spatial ordering (from 0 to 15) of the provinces. The spatial order of the 'neighbourhood' for each province was fixed on the basis of the shortest physical distance between the main cities of the provinces ${ }^{13}$. With assumption on the given ordering of the spatial connections for each province the matrices of correlations of detrended and deseasonalized time series of the unemployment rate for time lags from 0 to 12 were computed. The correlations for Kujawsko-pomorskie (Kuyavian-Pomeranian) province are shown in figure l. From this plot we can see that the correlations decline considerably as the time lags grow. The analogous regularity for the spatial shifts is less clear.

For the purpose of choosing the spatial 'neighbours' significantly connected with regard to the unemployment rate for each province, the partial autocorrelations along the ordering of the provinces were used. For example, the settlements for the K.-p. province are given in table 4. Figures 2-4 show the scope of connections of the K.-p. province with other provinces at lag 1, 2 and 3, respectively. Table 5 reports the number of initially selected 'neighbouring' provinces for each province. Simultaneously in table 5 we present the full specification of the dependence structure in the VAR model. After the estimation and verification of the model its final version was obtained. The model equation for the Kujawsko-pomorskie is described in table 6.

Finally, a residual analysis was carried out to investigate the relevance of the fitted VAR model. In particular, the spatio-temporal correlation structure was estimated. The structure was compared with an analogous one obtained

${ }^{13}$ As it was mentioned in Section 3, other orderings can be considered as well. In the study the alternative spatial orders have been established on the basis an economic distance between provinces. The economic distance was calculated according to the formula (cf. Pietrzak, 2010, p. 82): $\mathrm{d}_{\mathrm{ij}}=\sum_{\mathrm{k}=1}^{\mathrm{K}-1}\left|\mathrm{x}_{\mathrm{ki}, \mathrm{t}}-\mathrm{x}_{\mathrm{kj}, \mathrm{t}}\right|^{\delta}+\frac{1}{\tau}\left|\mathrm{x}_{\mathrm{Ki}, \mathrm{t}-\tau}-\mathrm{X}_{\mathrm{K}, \mathrm{t}-\tau}\right|^{\delta}$, where $\mathrm{X}_{\mathrm{k}}, \mathrm{k}=1, \ldots, 4$ denote the variables used to assess the economic potential of individual provinces, i.e.: $\mathrm{X}_{1}$ - business entities, $\mathrm{X}_{2}$ - GDP per capita, $\mathrm{X}_{3}$ - average salaries, $\mathrm{X}_{4}$ - investments; $\tau=6, \delta=0.5$. Because economically similar provinces as well as economically distant can interact with regard to unemployment rates, the rankings of provinces were used to check that identified by physical distance regions, correlated in terms of the phenomenon studied, are rather similar or unlike in economic terms. 
for the residuals from the univariate modelling. Tables 2 and 7 present the correlations at lag one for the both approaches considered, i.e. for the univariate modelling and the VAR model respectively. We can see that the residuals from the VAR model have much lower correlations than the others. It means that autoregressive models with spatial structure reflect better the spatio-temporal dependence in phenomenon considered. This result is in line with a conclusion in this respect by de Luna \& Genton (2004, pp. 292-293).

\section{Conclusion}

The use of the concept of the conditional, with regard to space dimension, random field simplifies the econometric analysis of the spatio-temporal processes. The multi-equation models for the vector of time series, e.g. in the form of VAR model, are constructed. The purpose of the empirical example was the repetition and extension of the previous studies (Szulc, 2006; 2008) to verify whether the order, established in an arbitrary way, of the connections in time and space across the provinces allows us to specify the logical, convincing structure of the spatial and time lags for an appropriate econometric model of the unemployment rate.

Previous researches as well as this study have showed that there is some evidence of spatial dependence according to the physical distance. However, sometimes the regions appear to be related to others regardless of their geographical proximity. Nevertheless, taking into consideration the spatial orders, even based on the physical distance, in the model constructed allows us to make a better fit of the spatio-temporal structure of the connections. Additionally, the confrontation of the identification of 'neighbourly' connections in the geographical aspect with the economic similarity of the related regions allows us to answer the question whether the model identifies well the economic neighbours. In the study it was found that economically similar regions, especially after some time, have a strong impact in terms of unemployment even if they are distant.

\section{References}

André, M., Dabo-Niang, S., Soubdhan, T., \& Ould-Baba, H. (2016). Predictive spatio-temporal model for spatially sparse global solar radiation data. Energy, 111. doi:10.1016/j.energy.2016.06.004.

Anselin, L. (1988). Spatial econometrics: methods and models. Dordrecht: Kluwer Academic.

Arbia, G. (1989). Spatial data configuration in statistical analysis of regional economics and related problems. Dordrecht: Kluwer Academic.

Arbia, G. (2006). Spatial econometrics: statistical foundations and applications to regional convergence. Berlin: Springer.

Arbia, G., \& Prucha, I.R. (2013). Editorial. Spatial Economic Analysis, 8(3). 
Arbia, G., Espa, G., \& Giuliani, D. (2013). Conditional vs. unconditional industrial agglomeration: disentangling spatial dependence and spatial heterogeneity in the analysis of ICT firms' distribution in Milan (Italy). Journal of Geographical Systems, 15(1). doi:10.1007/s10109-012-0163-2.

Arbia, G., Espa, G., \& Quah, D. (2008). A class of spatial econometric methods in the empirical analysis of clusters of firms in space. Empirical Economics, 34(1). doi:10.1007/s00181-007-0154-1.

Arbia, G., Espa, G., Giuliani, G.D., \& Mazzitelli, A. (2010). Detecting the existence of space-time clusters of firms. Regional Science and Urban Economics, 40(5). doi:10.1016/j.regsciurbeco.2009.10.004.

Bennett, J.R. (1979). Spatial time-series analysis: forecasting and control. London: Pion.

Bronars, S.G., \& Jansen, D.W. (1987). The geographic distribution of unemployment rates in the U.S.: a spatial-time series analysis. Journal of Econometrics, 36(3). doi:10.1016/0304-4076(87)90002-9.

Case, A.C. (1991). Spatial patterns in household demand. Econometrica, 59(4). doi:10.2307/2938168.

Case, A.C., Rosen, H.S., \& Hines, J.R. (1993). Budget spillovers and fiscal policy independence: evidence from the states. Journal of Public Economics, 52(3). doi:10.1016/0047-2727(93)90036-S.

Christakos, G. (2017). Spatiotemporal random fields: theory and applications. Amsterdam: Elsevier.

Cliff, A.D., \& Ord, J.K. (1973). Spatial autocorrelation. London: Pion.

Conley, T.G. (1999). GMM estimation with cross sectional dependence. Journal of Econometrics, 92(1). doi:10.1016/s0304-4076(98)00084-0.

Conley, T.G., \& Ligon, E.A. (2002). Economic distance and cross-country spillovers. Journal of Economic Growth, 7. doi:10.1023/A:1015676113101.

Conley, T.G., \& Topa, G. (2002) Spatio-economic distance and spatial patterns in unemployment. Journal of Applied Econometrics, 17(4). doi:10.1002/ jae. 670 .

Dahl, C.M., \& Gonzalez-Rivera, G. (2003a). Identifying nonlinear components by random fields in the US GNP growth: implications for the shape of the business cycle. Studies in Nonlinear Dynamics \& Econometrics, 7(1). doi:10.2202/1558-3708.1123.

Dahl, C.M., \& Gonzalez-Rivera, G. (2003b). Testing for neglected nonlinearity in regression models: a collection of new tests based on the theory of random fields. Journal of Econometrics, 114(1). doi:10.1016/s0304-4076(02)00222-1.

de Luna, X., \& Genton, M.G. (2004). Spatio-temporal autoregressive models for U.S. unemployment rate. In J.P. LeSage, \& R.K. Pace (Eds.), Spatial and spatiotemporal econometrics. Amsterdam: Elsevier. doi:10.1016/ s0731-9053(04)18009-2.

de Luna, X., \& Genton, M.G. (2005). Predictive spatio-temporal models for spatially sparse environmental data. Statistica Sinica, 15(2). 
Elhorst, J.P. (2010). Dynamic models in space and time. Geographical Analysis, 33(2). doi:10.1111/j.1538-4632.2001.tb00440.x.

Elhorst, J.P. (2012). Dynamic spatial panels: models, methods, and inferences. Journal of Geographical Systems, 14 (1). doi:10.1007/s10109-011-0158-4.

Elhorst, J.P. (2014). Spatial econometrics: from cross-sectional data to spatial panels. Heidelberg: Springer.

Epperson, B.K. (2000). Spatial and space-time correlations in ecological models. Ecological Modelling, 132(1-2). doi:10.1016/s0304-3800(00)00305-7.

Giacomini, R., \& Granger, C.W.J. (2004). Aggregation of space-time processes. Journal of Econometrics, 118(1-2). doi:10.1016/s0304-4076(03)00132-5.

Guyon, X. (1995). Random fields on a network: modelling, statistics and applications. New York: Springer.

Haggett, P., Cliff, A.D., \& Frey, A. (1977). Locational analysis in human geography. London: Edward Arnold.

Haining, R. (1990). Spatial data analysis in the social and environmental sciences. Cambridge: Cambridge University Press.

Ippoliti, L., Romagnoli, L., \& Arbia, G. (2013). A Gaussian Markov random field approach to convergence analysis. Spatial Statistics, 6. doi:10.1016/j. spasta.2013.07.005.

Jenish, N., \& Prucha, I.R. (2009). Central limit theorems and uniform laws of large numbers for arrays of random fields. Journal of Econometrics, 150(1). doi:10.1016/j.jeconom.2009.02.009.

Knopov, P.S. (1999). Markov fields and their applications in economics. Journal of Mathematical Sciences, 97(2). doi:10.1007/bf02366382.

Nummelin, E. (2000). Large deviations of random vector fields with applications to economies. Advances in Applied Mathematics, 24(3). doi:10.1006/ aama.1999.0668.

Pfeifer, P.E., \& Deutsch, S.J. (1980). A three-stage iterative procedure for space-time modelling. Technometrics, 22(1). doi:10.2307/1268381.

Pietrzak, M.B. (2010). Application of economic distance for the purposes of a spatial analysis of the unemployment rate for Poland. Oeconomia Copernicana, 1(1). doi:10.12775/oec.2010.005.

Przybycin, Z. (1992). Zastosowanie pól losowych w ekonomicznych modelach przestrzennych. Katowice: AE w Katowicach.

Quah, D. (1993). Empirical cross-section dynamics in economic growth. European Economic Review, 37(2-3). doi:10.1016/0014-2921(93)90031-5.

Statistics Poland. (2019). Local data bank. Retrieved 22.06.2019 from https:// bdl.stat.gov.pl.

Szulc, E. (2006). Specification of the dynamic model with the spatial structure of connections. Dynamic Econometric Models, 7.

Szulc, E. (2008). Modelowanie dynamicznego procesu ekonomicznego z przestrzenną strukturą zależności. In: J. Pociecha (Ed.), Modelowanie i prognozowanie zjawisk gospodarczych. Kraków: UE w Krakowie. 
Topa, G. (2001). Social interactions, local spillovers and unemployment. Review of Economic Studies, 68(2). doi:10.1111/1467-937x.00169.

Vega, S.H., \& Elhorst, J.P. (2014). Modelling regional labour market dynamics in space and time. Papers in Regional Science, 93(4). doi:10.1111/pirs.12018.

Zieliński, Z. (2002). Ekonometryczne modele pól losowych: postawienie problemu, podstawowe pojęcia i określenia, wytyczne kierunków badań. In Z. Zieliński, Analiza ekonomicznych procesów stochastycznych: pisma wybrane. Toruń: UMK.

\section{Acknowledgements}

Author contributions: author has given an approval to the final version of the article.

Funding: this research was funded by the Nicolaus Copernicus University in Torun, Faculty of Economic Sciences and Management statutory sources. 


\section{Appendix}

Table 1.

Trend-seasonal and autoregressive structure of the individual time series

\begin{tabular}{|c|c|c|c|c|c|c|c|c|}
\hline Providence & Dln. & K.-p. & Lbl. & Lbs. & Łdz. & Młp. & Mzw. & Opl. \\
\hline trend* & + & + & + & + & + & + & + & + \\
\hline seasonality & + & + & + & + & + & + & + & + \\
\hline order of autoregression** & 2 & 1 & 3 & 1 & 1 & 1 & 1 & 2 \\
\hline Province & Pdk. & Pdl. & Pmr. & Śls. & Śwt. & W.-m. & Wlk. & Zch. \\
\hline trend* & + & + & + & + & + & + & + & + \\
\hline seasonality & + & + & + & + & + & + & + & + \\
\hline order of autoregression** & 2 & 2 & 1 & 1 & 2 & 2 & 1 & 2 \\
\hline
\end{tabular}

Note:

* the threshold (sectional) trends were fitted. The first part covered the period from January 2011 to April 2014, and the second one concerned the period from May 2014 to April 2019;

** chosen by the partial autocorrelation function (PACF);

+ denotes a presence of the trend and seasonal components.

The abbreviations of Polish names of the provinces, except for the compound names, were created with the first three consonants of each of the name, i.e.: Dln. - Dolnośląskie, Lbl. — Lubelskie, Lbs. — Lubuskie, Łdz. — Łódzkie, Młp. — Małopolskie, Mzw. — Mazowieckie, Opl. — Opolskie, Pdk. — Podkarpackie, Pdl. — Podlaskie, Pmr. — Pomorskie, Śls. — Śląskie, Śwt. — Świętokrzyskie, Wlk. — Wielkopolskie, Zch. — Zachodniopomorskie. For the compound names they are: K. -p. Kujawsko-pomorskie, W.-m. - Warmińsko-mazurskie.

Source: Own preparation. 
|

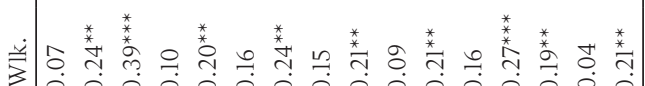

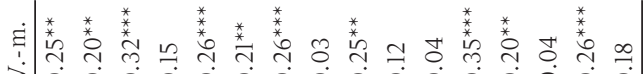

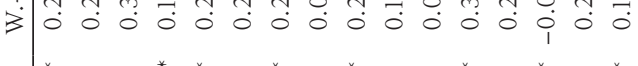

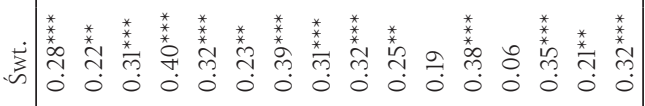

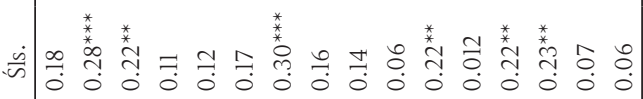

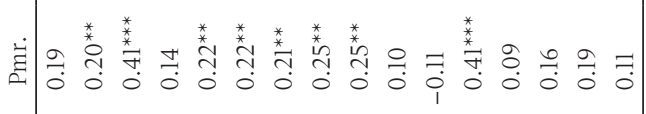
离

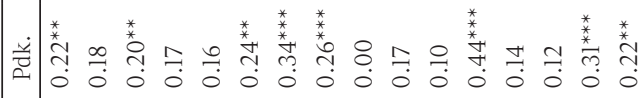

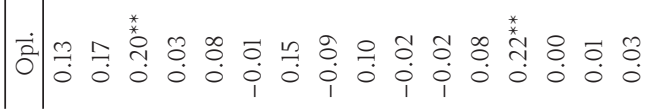
นก

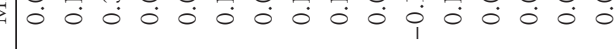

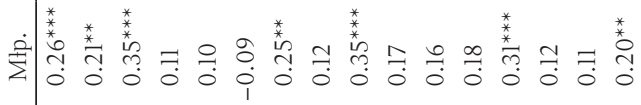

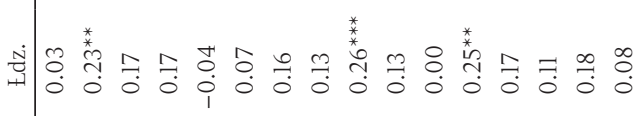

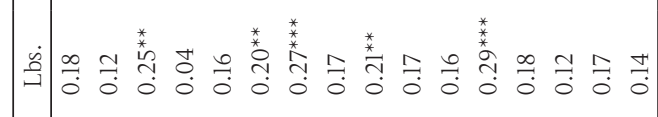

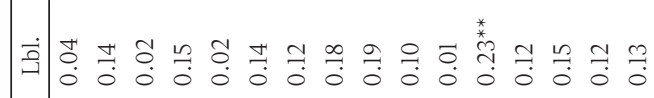




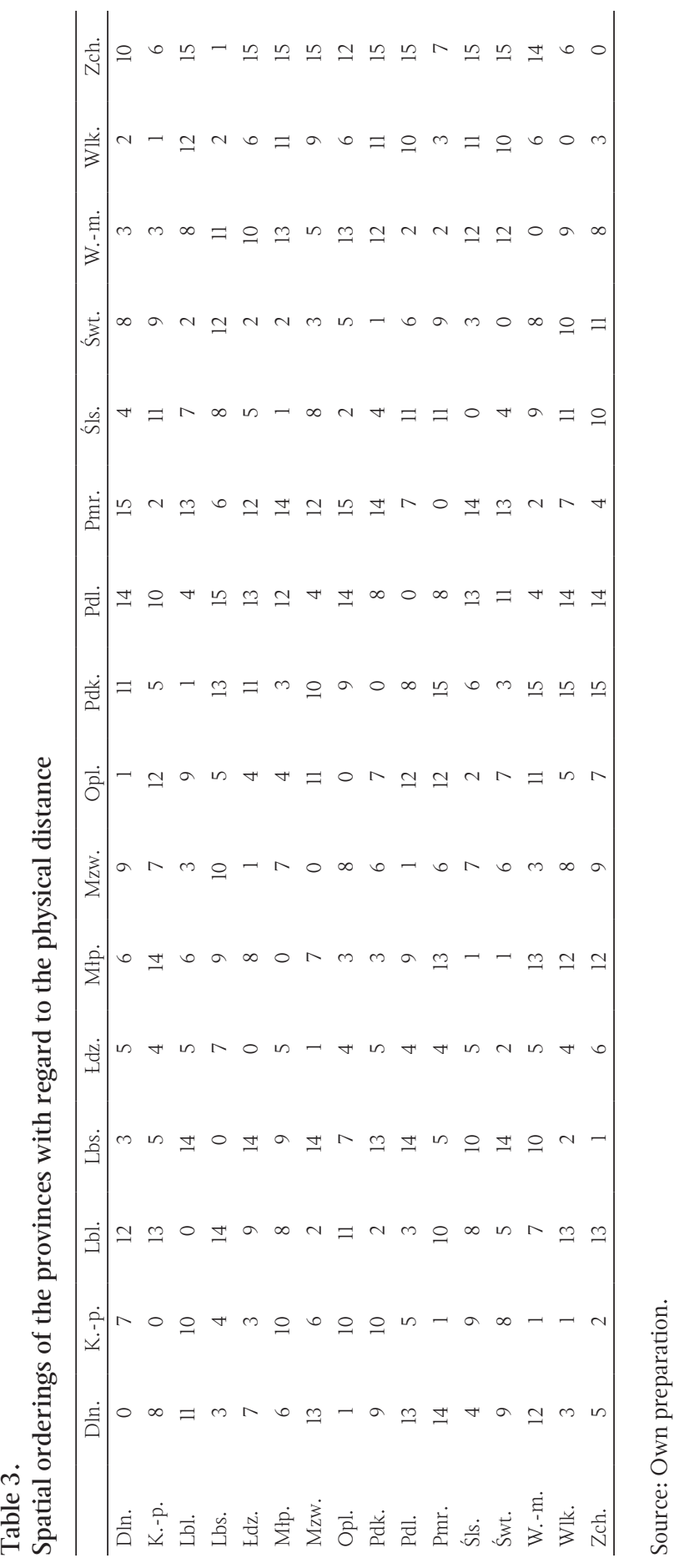




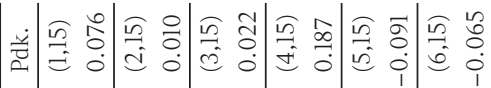

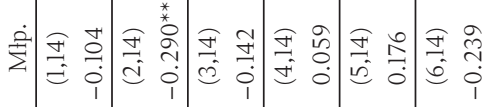

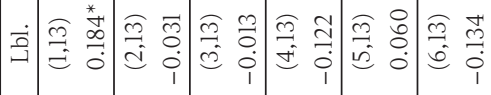

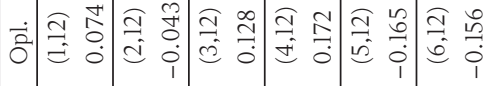

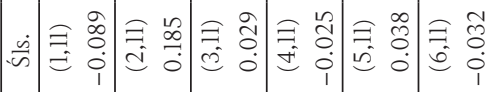

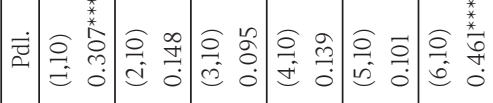

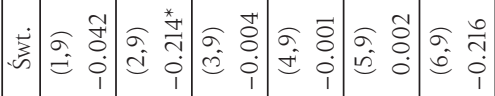

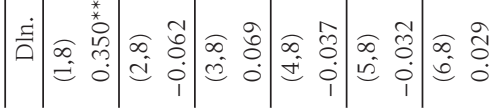

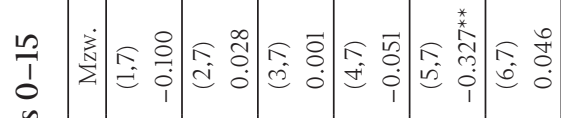

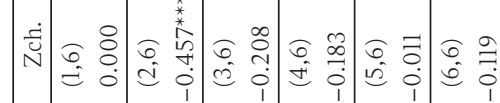

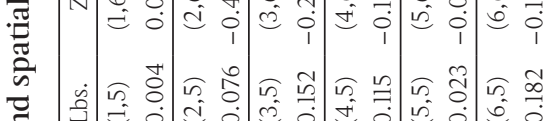

تُ

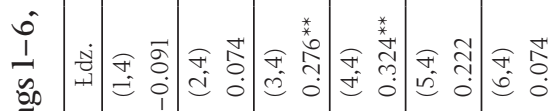

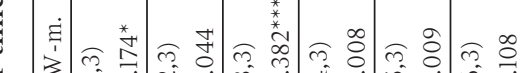

훙

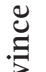

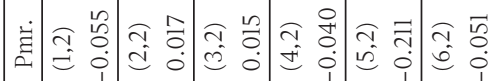

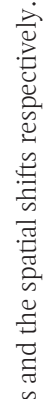

$\because \quad \frac{0}{\square}$

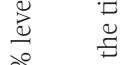

ㅇำ

$\Xi$

幽苛

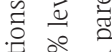

in

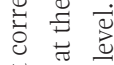

苛 苨

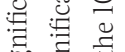

늘

ì

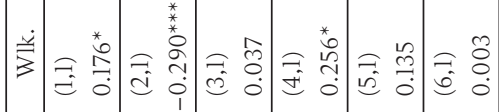


Table 5.

Structure of spatio-temporal dependence in the VAR model

\begin{tabular}{|c|c|c|c|c|c|c|c|c|}
\hline Lag & Dln. & K.-p. & Lbl. & Lbs. & Łdz. & Mtp. & Mzw. & Opl. \\
\hline 1 & 8 & 11 & 12 & 9 & 13 & 11 & 14 & 14 \\
\hline 2 & 16 & 7 & 1 & 16 & 7 & 3 & 8 & 13 \\
\hline 3 & 1 & 5 & 9 & 12 & 4 & 1 & 6 & 14 \\
\hline 4 & 2 & 5 & 2 & 8 & 0 & 2 & 2 & 5 \\
\hline 5 & 10 & 0 & 6 & 11 & 0 & 0 & 2 & 0 \\
\hline 6 & 6 & 0 & 7 & 0 & 0 & 0 & 0 & 0 \\
\hline Lag & Pdk. & Pdl. & Pmr. & Śls. & Śwt. & W.-m. & Wlk. & Zch. \\
\hline 1 & 11 & 14 & 15 & 15 & 10 & 16 & 15 & 15 \\
\hline 2 & 12 & 12 & 8 & 10 & 16 & 14 & 13 & 13 \\
\hline 3 & 13 & 5 & 5 & 0 & 13 & 6 & 7 & 2 \\
\hline 4 & 4 & 5 & 0 & 0 & 6 & 0 & 0 & 0 \\
\hline 5 & 0 & 5 & 0 & 0 & 0 & 0 & 0 & 0 \\
\hline 6 & 0 & 0 & 0 & 0 & 0 & 0 & 0 & 0 \\
\hline
\end{tabular}

Source: Own preparation.

Table 6.

Results of the estimation and verification of the equation for the K.-p. province

\begin{tabular}{|c|c|c|c|c|c|}
\hline Variable & Parameter estimate & $\mathrm{p}$-value & Variable & Parameter estimate & $\mathrm{p}$-value \\
\hline \multicolumn{3}{|c|}{ trend and seasonality } & $d m 8$ & -0.4434 & 0.0000 \\
\hline constl & 3.9481 & 0.0000 & $d m 9$ & -0.4847 & 0.0000 \\
\hline tl & -0.0127 & 0.0055 & $d m 10$ & -0.5499 & 0.0000 \\
\hline const2 & 3.3737 & 0.0000 & $d m l 1$ & -0.1409 & 0.0012 \\
\hline t2 & -0.0306 & 0.0000 & \multicolumn{3}{|c|}{ autoregression } \\
\hline$d m l$ & 0.3167 & 0.0000 & K.-p._lagl & 0.8149 & 0.0000 \\
\hline$d m 2$ & -0.2599 & 0.0005 & Dln._lagl & 0.3109 & 0.0002 \\
\hline$d m 3$ & -0.4518 & 0.0000 & Edz._lagl & 0.2789 & 0.0000 \\
\hline$d m 4$ & -0.4515 & 0.0000 & Mzw._lagl & 0.2021 & 0.0351 \\
\hline$d m 5$ & -0.2964 & 0.0000 & Śwt._lagl & -0.0892 & 0.0567 \\
\hline$d m 6$ & -0.4189 & 0.0000 & Zch._lag2 & -0.3244 & 0.0000 \\
\hline$d m 7$ & -0.3103 & 0.0000 & Wlk._lag3 & -0.3159 & 0.0000 \\
\hline \multicolumn{3}{|c|}{ goodness of fit } & \multicolumn{3}{|c|}{ residual autocorrelation } \\
\hline \multicolumn{2}{|c|}{ R-square } & 0.9996 & DW st & \multicolumn{2}{|c|}{-1.6828} \\
\hline
\end{tabular}

Source: Own preparation. 


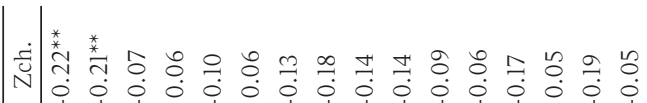

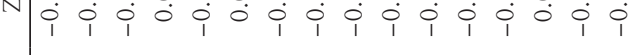

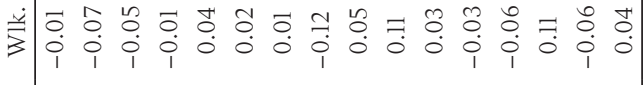

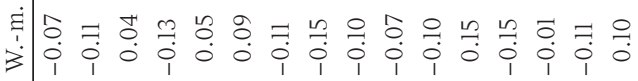

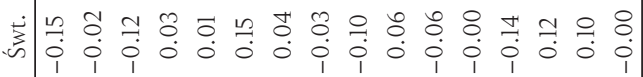

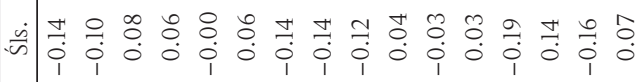

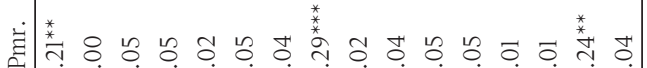

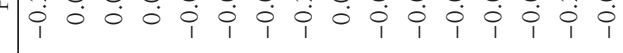

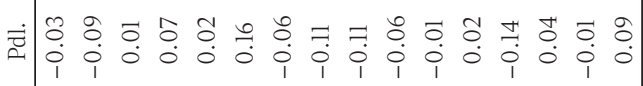

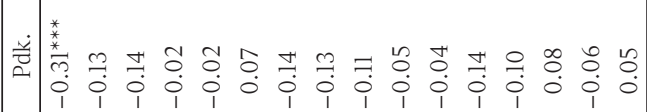

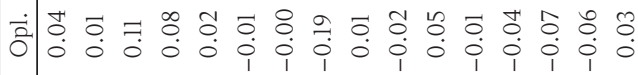

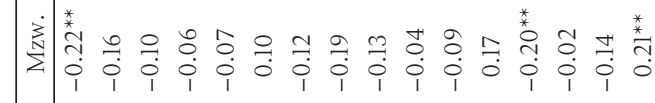

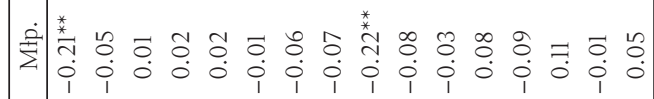

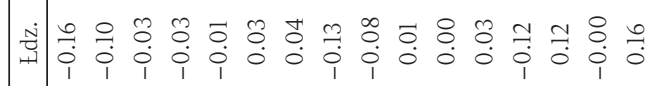

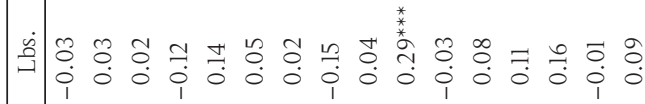
至

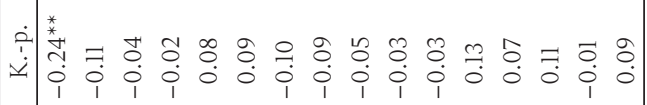

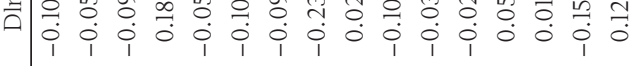


Figure 1.

Spatio-temporal correlations for K.-p. province for the time lags 0-12, and the spatial shifts $0-15$

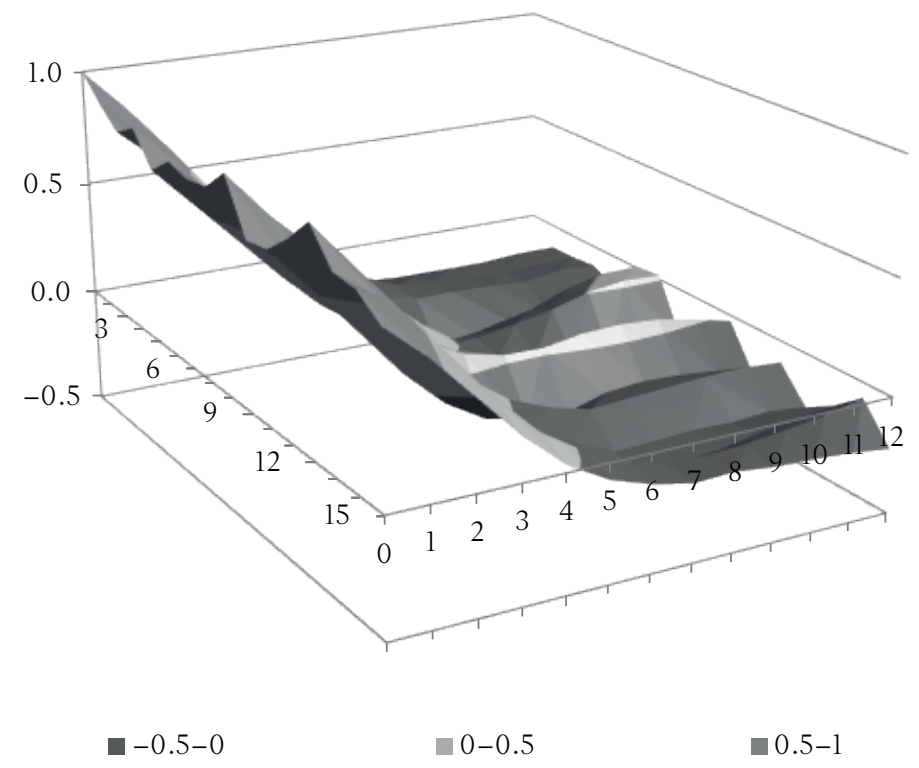

Source: Own preparation. 
Figure 2.

Scope of connections of the K.-p. province with other provinces at lag 1 (by the partial correlations)

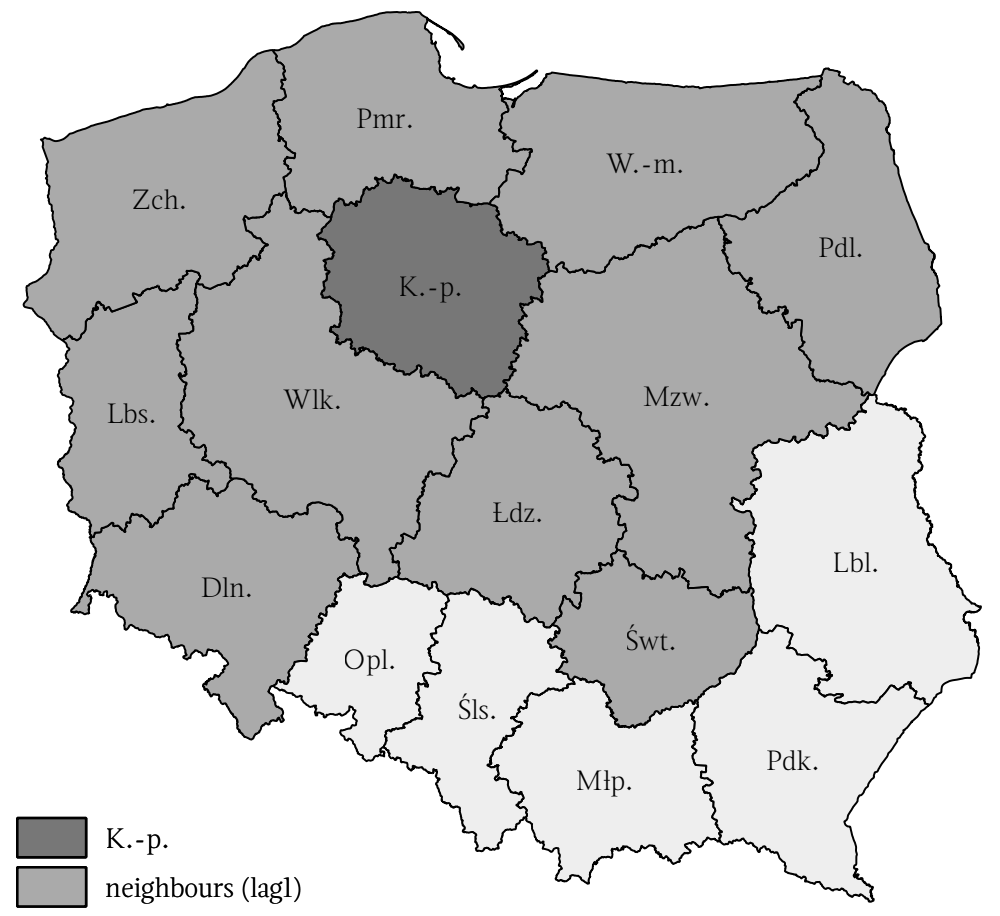

Source: Own preparation. 
Figure 3.

Scope of connections of the K.-p. province with other provinces at lag 2 (by the partial correlations)

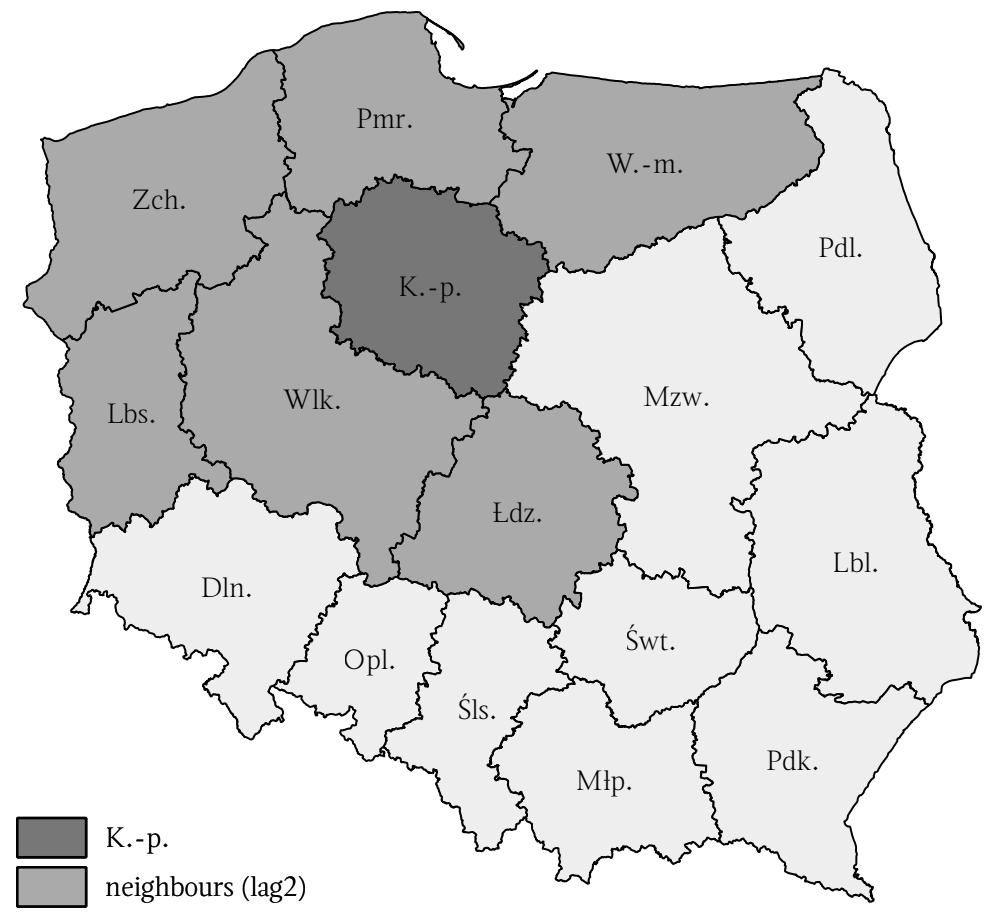

Source: Own preparation. 
Figure 4.

Scope of connections of the K.-p. province with other provinces at lag 3 (by the partial correlations)

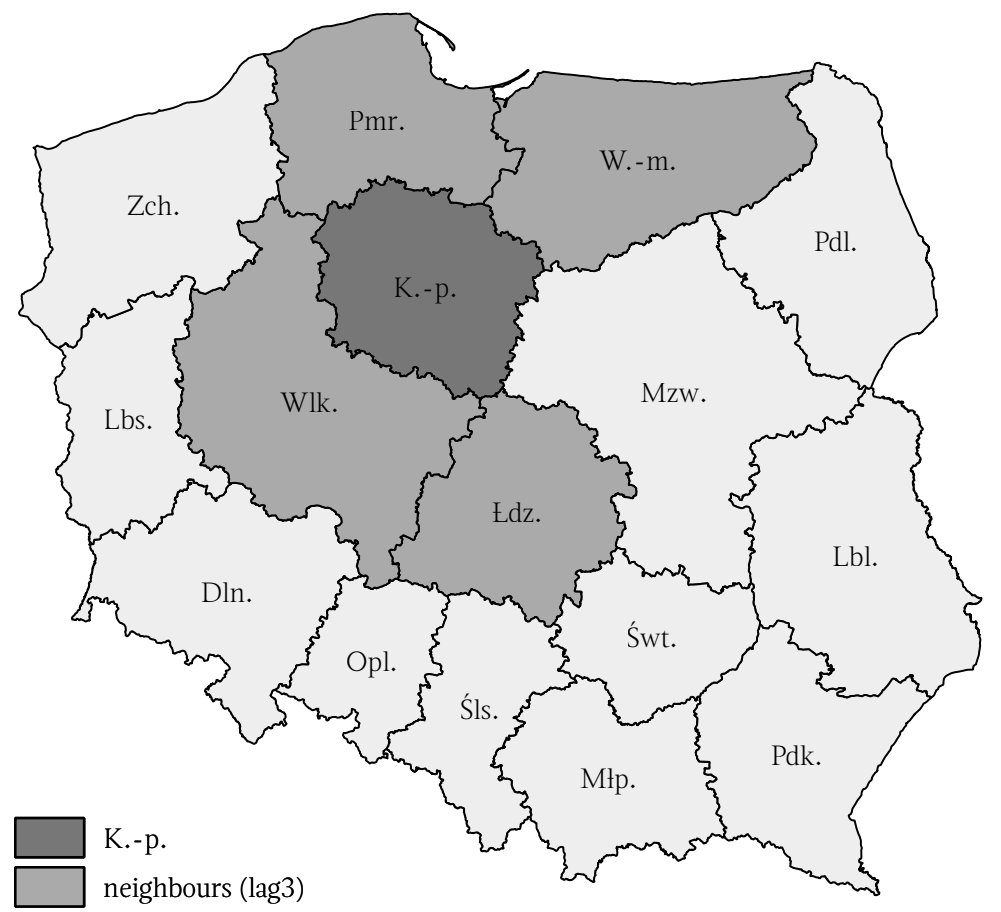

Source: Own preparation. 